\title{
Processos de degradação socioambiental: os impactos das atividades produtivas desenvolvidas no perímetro irrigado de São Gonçalo - Paraíba/Brasil
}

\section{Socioenvironmental degradation processes: impacts of productive activities developed in the irrigated perimeter of São Gonçalo - Paraíba/Brazil}

Jânesson Gomes Queiroz - Mestre em Planejamento e Dinâmicas Territoriais no Semiárido, pela Universidade do Estado do Rio Grande do Norte (UERN). Professor da Escola Municipal Mário Alves Diniz (João Dias - RN) e da Escola Municipal Abraão Cavalcante Bessa (Taboleiro Grande - RN). E-mail: janessongeografo@hotmail.com

Larissa da Silva Ferreira Alves - Doutora em Geografia, pela Universidade Federal do Ceará (UFC). Professora da Universidade do Estado do Rio Grande do Norte (UERN). E-mail: larissaferreira@uern.br

Jairo Bezerra Silva - Doutor em Sociologia, pela Universidade Federal da Paraíba (UFPB). Professor da Universidade Estadual da Paraíba. E-mail: jairrobezerra@hotmail.com

\section{Resumo}

O objetivo deste artigo é analisar os principais processos de degradação socioambiental desencadeados a partir da implementação do Perímetro Irrigado de São Gonçalo (PISG), ocorridos no início da década de 1970, no município de Sousa - Paraíba. Desde o referido período, algumas atividades produtivas vêm sendo praticadas no PISG mediante inadequações relativas às precauções ambientais devidas, como desmatamento desenfreado, uso excessivo de agrotóxico e fertilizantes químicos, queimadas desordenadas e irrigação inadequada. Quanto à abordagem, o estudo adentrou meandros qualitativos e quantitativos, e em relação aos procedimentos, englobou uma pesquisa bibliográfica, documental e de campo, que foram articuladas aos conceitos teóricos da Capitalização da Natureza. Esse aporte teórico-metodológico é a 'corda' que sustenta a análise acerca do objeto de estudo. Mediante essa discussão, concluímos que os processos de degradação socioambiental revelam um movimento oposto entre exploração dos recursos naturais e desenvolvimento sustentável, dinâmica essa marcante desde a origem do PISG.

\section{Palavra-chave}

Semiárido. Irrigação. Mercantilização da natureza. Degradação socioambiental. Declínio produtivo.

\begin{abstract}
The aim of this article is to analyze the main socioenvironmental degradation processes triggered by the implementation of the São Gonçalo Irrigated Perimeter (PISG), which occurred in the early 1970s, municipality of Sousa - Paraíba. Since that period, some productive activities have been practiced in PISG due to inadequacies related to due environmental precautions, such as rampant deforestation, excessive use of pesticides and chemical fertilizers, disordered fires and inadequate irrigation. As for the approach, the study entered qualitative and quantitative intricacies, and in relation to the procedures, it included a bibliographical, documentary and field research, which were articulated to the theoretical concepts of the Capitalization of Nature. This theoreticalmethodological contribution is the 'rope' that supports the analysis of the object of study. Through this discussion, we concluded that the socio-environmental degradation processes reveal an opposite movement between the exploitation of natural resources and sustainable development, a dynamic that has been striking since the origin of the PISG.
\end{abstract}

\section{Keywords}

Semiarid. Irrigation. Commodification of nature. Socioenvironmental degradation. Productive decline. 


\section{INTRODUÇÃO}

A história da humanidade vem sendo marcada pela transformação do espaço geográfico mediante conflitos e tensões, principalmente em torno dos recursos naturais. O referido processo revela que, ao tempo que as técnicas são aprimoradas, a dominação/apropriação da natureza se torna mais evidente, sobretudo por meio da lógica mercantil (SANTOS; SILVEIRA, 2006). Essa dinâmica socionatural vem sendo caracterizada pela exploração predatória e capitalizadora das riquezas naturais, nutrindo o sistema capitalista e desnutrindo as condições de um futuro melhor para as próximas gerações (LEFF, 2006; NASCIMENTO, 2006).

A exploração insustentável da vegetação, do solo, da água e de outros recursos naturais vem provocando a degradação das matas, das florestas, dos solos, dos rios, dos córregos e dos mares. Em decorrência disso, há o comprometimento do progresso das civilizações, uma vez que a baixa qualidade e quantidade das riquezas naturais podem condicionar negativamente o desenvolvimento, em seu sentido estrito. Nesta perspectiva, devido sua complexidade, a degradação socioambiental vem assumindo grande destaque na pauta do debate científico e político sobre o desenvolvimento (NASCIMENTO, 2006).

Neste contexto, encontra-se o Perímetro Irrigado de São Gonçalo (PISG), que foi implantado no início da década de 1970. No entanto, do referido período até então algumas alterações no arranjo natural da paisagem vêm sendo registradas, as quais se relacionam principalmente ao desenvolvimento de determinadas atividades produtivas em descompasso com a sustentabilidade (GOMES, 2005; SILVA NETO, 2013; SIQUEIRA et al., 2018).

No PISG, as atividades agropecuárias foram (e algumas ainda são) praticadas com base em técnicas tradicionais/defasadas, a exemplo do desmatamento das margens do rio Piranhas, para a construção de estradas ou a introdução de culturas irrigadas; do uso excessivo de agrotóxicos e fertilizantes químicos, visando melhorar a quantidade e a qualidade da produção; da prática de queimadas descontroladas, com vistas à limpeza dos terrenos para a formação de pastagens e/ou para o plantio; além da inundação de áreas plantadas, visando irrigar culturas diversas, como arroz, coco e banana. Ao longo do tempo, essas atividades vêm provocando alguns impactos danosos na qualidade ambiental, além de conseguintes efeitos na produção agropecuária e na qualidade de vida da população (GOMES, 2005; SILVA et al., 2017). 
Assim, conforme Nascimento (2006) a degradação socioambiental é entendida como qualquer alteração adversa do meio ambiente, sendo provocada pela ação humana. Os efeitos da alteração adversa da vegetação, dos solos, dos recursos hídricos e da biodiversidade podem significar a redução da qualidade de vida das populações afetadas pelo conjunto combinado desses fatores. Diante do exposto, e com base no debate proposto por Nunes e Sousa (2018), consideramos que as atividades humanas coordenadas mediante os interesses capitalistas são as principais causadoras da degradação socioambiental, cabe aqui citar como exemplo os grandes projetos de irrigação desenvolvidos no semiárido brasileiro.

Nesta perspectiva, o objetivo do presente artigo consiste em analisar os principais processos de degradação socioambiental desencadeados no PISG mediante o desenvolvimento de algumas atividades agropecuárias. Na seção a seguir apresentaremos as bases teórico-metodológicas da pesquisa, as quais articulam e sustentam as discussões aqui propostas.

\section{BASES TEÓRICO-METODOLÓGICAS}

A área de estudo compreende o Perímetro Irrigado de São Gonçalo (PISG) ${ }^{1}$, cujo território se estende por 5.548 hectares de terras localizadas no Vale do rio Piranhas, município de Sousa (PB), distando aproximadamente 15 $\mathrm{km}$ da cidade de Sousa e $440 \mathrm{~km}$ da cidade de João Pessoa, capital do Estado (Figura 1), segundo informações do Departamento Nacional de Obras Contra as Secas (DNOCS, 2020). No que se refere ao quantitativo populacional, o referido Perímetro é formado por uma população maior que a de muitos municípios do Semiárido brasileiro, são 7.862 habitantes, os quais estão assentados em quatro áreas, a sede, São Gonçalo, com 2.510, e três agrovilas, que são: Núcleo I, com 2.212; Núcleo II, com 2.040; e o Núcleo III, com 1.100 habitantes (ARAÚJO et al., 2018).

Está inserido em região de clima semiárido, com chuvas irregulares no tempo e no espaço, concentradas nos meses de janeiro a maio, estabelecendo um longo período de estiagem nos meses restantes do ano (DNOCS, 2020). Conforme dados da Empresa Brasileira de Pesquisa Agropecuária (EMBRAPA), a pluviometria média é de 800 milímetros anuais (EMBRAPA, 2006). Na região do PISG, as temperaturas variam entre $25^{\circ} \mathrm{C}$ a $38^{\circ} \mathrm{C}$, a umidade relativa do ar fica entorno de $64 \%$ e a evaporação média anual é de 3.056,6 milímetros, mais de três vezes maior que a pluviometria. O relevo é predominantemente aplainado, com altitude média de 235 metros acima do nível do mar. Os solos têm consistência que varia de arenosa a argilosa, com fertilidade natural oscilante entre boa e média. A vegetação típica da localidade é composta por caatinga, com espécies arbóreas, arbustivas, herbáceas, cactáceas e bromeliáceas (SILVA NETO, 2013). 
Figura 1 - Localização geográfica do PISG.

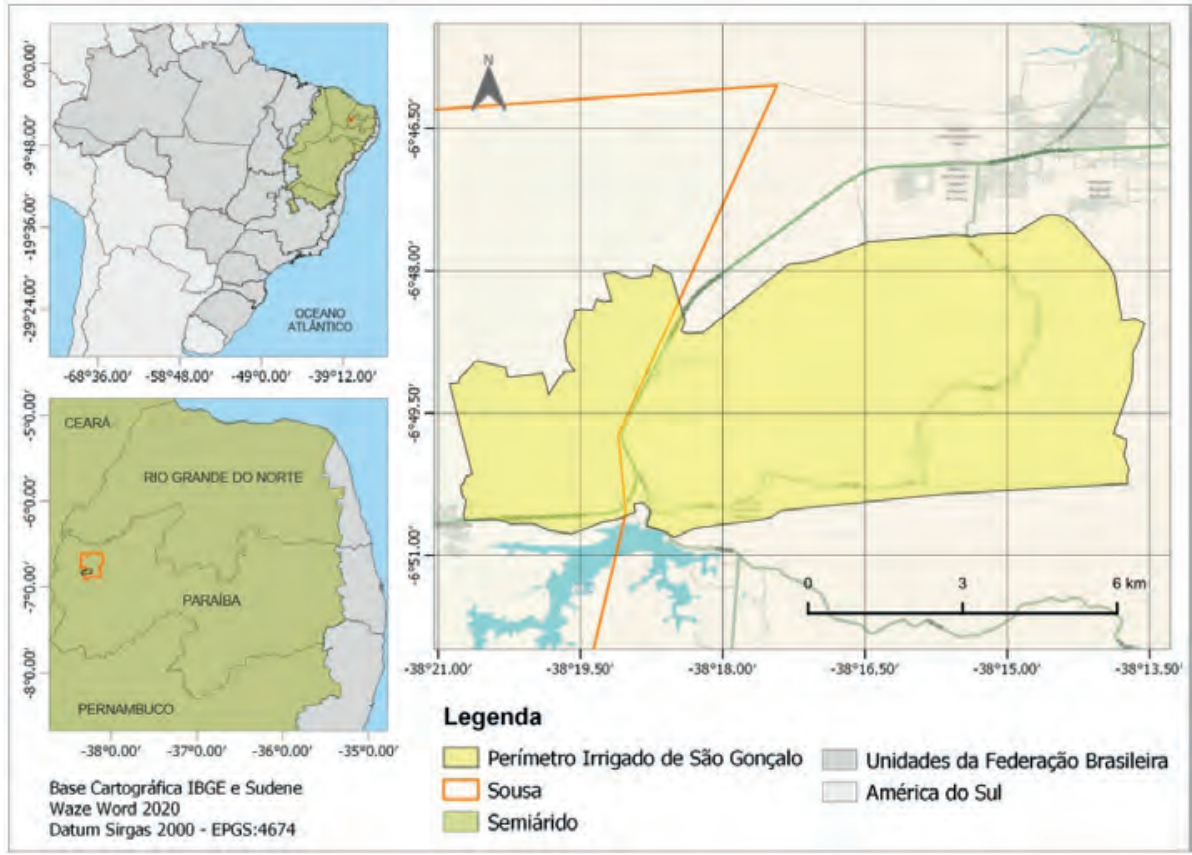

Fonte: os autores (2020).

Em relação à abordagem metodológica, o estudo adentrou meandros qualitativos e quantitativos. Conforme Polit e Hungler (2004) apud Gerhardt e Silveira (2009), o método qualitativo tende a delinear um caminho direcionado aos aspectos dinâmicos, holísticos e individuais da experiência humana, para apreender a totalidade no contexto daqueles que estão vivenciando uma determinada realidade. Já o método quantitativo tende a direcionar o pesquisador para a análise lógica do fenômeno estudado, esta pautada no raciocínio dedutivo, nas regras lógicas e nos atributos mensuráveis da experiência humana.

Neste sentido, em termos qualitativos, realizamos uma análise especialmente teórica, focalizada nas causas e nos efeitos socioeconômicos dos principais processos de degradação socioambiental desencadeados após a implantação do PISG. Em termos quantitativos, realizamos a complementação das discussões por meio de alguns dados numéricos e mensurações lógico-dedutivas relacionadas, sobretudo, ao contexto inerente aos desperdícios de água no processo de irrigação e à desestruturação do quadro socioeconômico do PISG.

No que se refere aos procedimentos metodológicos, o estudo englobou uma pesquisa bibliográfica, documental e de campo. Sobre a pesquisa bibliográfica, Trienta et al. (2014) aponta que esse instrumento tem relação 
direta com levantamentos do que já foi produzido como conhecimento científico, e por isso deve ser mapeado para auxiliar na construção de novos saberes. Realizamos essa pesquisa quando da revisão de literaturas científicas sobre o objeto de estudo. Assim, no que concerne à formação e 'evolução' socioeconômica do PISG, inclusive com vista às atividades humanas em descompasso com a sustentabilidade, estudamos as obras de Queiroz (1993), Gomes (2005), Silva Neto (2013), Soares (2018) e outros autores. Também articulamos a discussão aos preceitos geopolíticos da mercadorização dos recursos naturais com base na corrente teórica denominada de Capitalização da Natureza, sendo que os principais estudos utilizados foram os de Leff (2006), Santos e Silveira (2006) e Santos (2015).

A Capitalização da Natureza emergiu nos anos 1980 do século passado e se encontra em plena difusão no mundo científico. Essa corrente do pensamento pós-moderno estuda as armadilhas da expansão da globalização, buscando 'desbravar um campo minado' caracterizado por disputas/tensões, sobretudo inerentes à relação de dominação/apropriação dos humanos sobre a natureza em nome de um suposto desenvolvimento, o qual vem se atrelando às estratégias de transformação dos recursos naturais em dinheiro global (LEFF, 2006). Essa lógica mercantilista se encontra em plena disseminação no mundo ocidental, principalmente através do efeito de espraiamento provocado pela 'onda' neoliberal privatizante das riquezas naturais (SILVA et al., 2015).

Outras informações importantes à discussão proposta foram colhidas mediante levantamento documental, que segundo Marconi e Lakatos (2003), é caracterizado pelas fontes de coleta de dados, que podem ser escritas ou não, a exemplo de arquivos públicos (físicos ou online). Assim, reunimos informações contidas em documentos oficiais disponíveis na internet, como dados referentes à irrigação no PISG. Esses dados foram acessados principalmente no sítio do DNOCS. Por um lado, essa ferramenta foi útil à compreensão técnica quanto ao sistema de irrigação utilizado no PISG (inundação), e por outro lado, fomentou a ampliação da discussão sobre os impactos socioambientais relacionados a esse tipo de manejo hídrico.

Para melhor compreendermos o objeto da pesquisa, se fez necessário realizar seções de estudo de campo. A pesquisa in loco, segundo Giumbelli (2002), é uma ferramenta de estudo que permite uma aproximação mais intensa e harmoniosa entre pesquisador e a realidade pesquisada, com uma observação direta e situações de pesquisa que permitem uma posterior reflexão sobre os dados coletados. Com base nesta perspectiva teórica, colhemos os dados em campo em duas formas. Inicialmente, por meio da exploração observacional do 
espaço, visando, sobretudo, perceber alterações artificiais na paisagem física, e posteriormente, por meio do levantamento fotográfico de recortes paisagísticos indicadores de desarranjos socioambientais. Esses instrumentos possibilitaram relacionar a teoria à realidade pesquisada e aguçar nosso entendimento acerca dos processos de degradação socioambiental. Na seção a seguir, abordaremos a formação socioeconômica do PISG, com vista à atuação das forças de mercado.

\section{FORMAÇÃO SOCIOECONÔMICA DO PISG: UM PROCESSO DELINEADO PELA ATUAÇÃO DE MERCADO}

No início do século XX, o DNOCS ao tentar promover materialidade ao discurso de 'redenção' socioeconômica do Nordeste, implementou projetos desenvolvimentistas em várias áreas do Semiárido brasileiro (SANTOS; SILVEIRA, 2006; SILVA et al., 2015), especialmente na região de São Gonçalo, município de Sousa - Paraíba. Logo, a localidade representava um excelente palco para a apresentação das atrações orquestradas pelo órgão, principalmente devido à área ser entrecortada pelo curso das águas do rio Piranhas, ser formada por solos relativamente férteis, ser privilegiada por pluviometria média elevada, se comparada a outras áreas semiáridas e representar um nó de fluxos diversos na conexão com muitos pontos da Paraíba, por meio da PB-380 (Rodovia da Produção) e da Rodovia Federal BR-230. Servindo-se desses e de outros privilégios naturais e infra estruturais, desde a segunda década do século passado, o DNOCS vem atuando como um dos atores principais no processo de fomento ao 'desenvolvimento' dessa localidade encravada no Sertão paraibano e concebida como 'oásis sertanejo' (SILVA NETO, 2013; SOARES, 2018).

Utilizando-se do potencial natural e infra estrutural acima citado, o DNOCS implementou um dos primeiros projetos de irrigação do Semiárido, o Perímetro Irrigado de São Gonçalo (PISG), em 1973 (SOARES, 2018). Inicialmente, ocorreu a demarcação das terras, as quais foram destinadas principalmente à agricultura irrigada e à instalação de infraestrutura básica, como casas, escolas, postos administrativos e canais de irrigação (SILVA NETO, 2013). Os objetivos principais dessa política pública eram garantir a segurança alimentar das populações locais, fomentar teias de relações econômicas que pudessem articular a região ao mercado longínquo e evitar o êxodo rural (GOMES, 2005).

O PISG foi implantado com base nos mesmos moldes de assentamento oficial do DNOCS. O referido órgão também se utilizou de legislação própria para expropriar as terras pertencentes aos vazanteiros, pequenos criadores e fazendeiros e, posteriormente, para realizar a seleção dos assentados, os quais foram 
denominados de colonos. Com isso, o sistema produtivo primitivo foi interrompido para abrir espaço a outro modelo, o de mercado via irrigação (QUEIROZ, 1993).

Com a distribuição dos lotes de terras, que tinham áreas variando entre 3,5 e 5 hectares, e alguns já com plantações situadas, algumas culturas passaram a ser praticadas em maior escala, destacando-se a produção de arroz, coco, banana, goiaba, manga e algodão arbóreo, que normalmente eram comercializadas para fábricas do Estado do Pernambuco (QUEIROZ, 1993). Aos poucos, a elevação na produção fez iniciar um ciclo econômico no PISG, isto é, uma produção voltada ao abastecimento do mercado local, regional, nacional e até internacional (SILVA NETO, 2013).

No início da implantação do PISG, as práticas agrícolas eram prioritárias, assim, a pecuária era inibida pelo modelo produtivo instalado e proibida pelas autoridades locais representantes do DNOCS (SILVA NETO, 2013). Após a década de 1980, a pecuária ganhou terreno, abrindo espaço a uma relativa diversificação do setor produtivo (SILVA et al., 2017).

As décadas de 1990 e 2000 foram marcadas pela pujança da produção agropecuária, mesmo considerando alguns períodos de instabilidade na quadra chuvosa e relativas perdas, como em 1993 e 1998 (SOARES, 2018). Pós-2012, a produção agropecuária do PISG sofreu drásticas reduções, problemática associado a vários fatores, a exemplo dos processos de degradação socioambiental provocados pela intensificação da pressão de mercado sobre os principais produtos locais. Tal pressão induziu a utilização demasiada de alguns recursos naturais ao ponto do irracional modelo de superprodução se esbarrar, sobretudo, na escassez hídrica provocada principalmente pelos meandros da própria exploração mediada pelos princípios capitalistas impulsionadores do lucro (SILVA et al., 2017; SOARES, 2018, SIQUEIRA et al., 2018).

No próximo tópico discutiremos mais especificamente os liames da relação sociedade e natureza, esses inerentes à ordem capitalista no âmbito do PISG, focalizando a atuação do mercado como construtor de uma armadilha estruturada entre a exploração massiva dos recursos naturais e a capitalização de minorias sociais.

\section{O PISG SOB O 'APRISIONAMENTO' DE MERCADO: DA CAPITALIZAÇÃO DOS RECURSOS NATURAIS AO EMPODERAMENTO DE MINORIAS SOCIAIS}

Historicamente, a produção de base familiar desenvolvida no PISG se caracterizou pelo alinhamento ao projeto do DNOCS, cuja Autarquia Federal estabeleceu como objetivo principal a capitalização dos colonos (GOMES, 
2005). Delineada nessa diretriz, a produção foi expandida ao longo dos anos e ganhou terreno no plano de mercado, com destaque para as relações comerciais fomentadas com várias regiões do Brasil e até dos Estados Unidos da América (SILVA NETO, 2013).

Nas décadas de 1970 e 1980, os assentados (ou colonos) ainda estavam em processo de adaptação às regras estabelecidas pelo DNOCS. Neste sentido, algumas dificuldades ocorreram, como a demora para a fixação de algumas culturas e a obtenção de lotes de terras com extensões suficientes para produzir e garantir o sustento do grande número de integrantes das famílias, que geralmente eram mais de 10 pessoas (GOMES, 2005). Mesmo com as limitações à época, um produto aflorou no PISG, o arroz, que bateu recordes de produção, sendo uma das maiores do Estado da Paraíba, com aproximadamente 6 toneladas/ha/ano. A produção era comercializada, principalmente, para o Estado do Pernambuco e para a região de Sousa. Com o declínio da rizicultura no final da década de 1980, a produção de coco e banana assumiu, nas décadas seguintes, o posto de uma das maiores do Estado (SOARES, 2018). Em meio ao Semiárido, o arroz irrigado através da inundação, bem como outras atividades de exploração inadequada dos recursos naturais trazem à tona a necessidade de (re)pensarmos propósitos e ações em relação ao melhor aproveitamento do potencial socioambiental do Território.

Segundo Silva Neto (2013), a maior parte da produção de coco e banana era comercializada para o Rio de Janeiro, São Paulo, Brasília, Recife, João Pessoa e Estados Unidos (no caso dos EUA, a venda dos produtos era realizada para a Empresa Vita Good). Por outro lado, os produtos de origem pecuária (leite de vaca e carne bovina, ovina, caprina e suína, dentre outros) abasteciam principalmente o mercado da cidade de Sousa e região (ARAÚJO et al., 2018).

Principalmente a partir da década de 1990, o grande retorno financeiro proveniente da emergente transformação de grande parte dos recursos naturais do PISG em produtos agropecuários fez os produtores "encherem os olhos", isto é, ficarem hipnotizados por meio da magia do capital ${ }^{2}$. Vale salientar que esse processo de capitalização foi seletivo, beneficiando apenas uma minoria social, principalmente àqueles que transportavam e comercializavam seus produtos diretamente para o centro econômico do País, o Sudeste. A prosperidade financeira de determinados grupos de colonos incentivou os demais a buscarem produzir cada vez mais, numa corrida que os distanciava da conservação dos recursos naturais e os aproximava do capital, tornando o sistema produtivo do PISG aprisionado pelo mercado (QUEIROZ, 2019).

2 A título de ilustração, apenas em 2012 os produtores lucraram quase 20 milhões de reais (SILVA et al., 2017; SIQUEIRA et al., 2018). 
Conforme os ensinamentos de Santos (2015) em relação à integração entre os espaços relativamente isolados, é oportuno ressaltar o fato de que o mercado possivelmente foi um dos principais agentes construtores de teias de relações econômicas convergentes ao PISG, sobretudo impulsionadas pelos reflexos da globalização econômica pós-1990. Porém, nossa reflexão se debruça sobre o fato de que tais relações não tiveram tempo ${ }^{3}$ e capacidade logística-estrutural ${ }^{4}$, aspectos necessários à consolidação de uma racionalidade quanto à fluidez dos movimentos inerentes a regulação do consumo excessivo dos recursos naturais, às formas da produção, às trocas comerciais e à circulação financeira. Conforme Queiroz (2019), no PISG, a capitalização dos recursos naturais com lucros financeiros estratosféricos reduziu as possibilidades de regulamentação mercadológica da exploração, influenciando na exaustão ambiental e na desestruturação do próprio mercado. Aliás, tal racionalidade ambiental ainda não veio à tona no mundo ocidental. A seguir analisaremos os principais processos de degradação socioambiental desencadeados no PISG ao longo de sua história.

\section{A DEGRADAÇÃO SOCIOAMBIENTAL DESENCADEADA NO PISG}

Conforme Siqueira et al. (2018) e Queiroz e Rodrigues (2019), a exploração predatória de muitas das riquezas naturais do PISG o conduziu a uma espécie de "implosão" do equilíbrio ambiental, isto devido à produção expansiva, pressionada pela demanda de mercado e desregulada ambientalmente. Segundo Queiroz (2019), muitos colonos visando aumentar a produção praticaram desmatamentos, queimadas, usaram grandes quantidades de insumos químicos nas plantações e utilizaram volumes excessivos de água na irrigação. Esse modelo produtivo provocou o desencadeamento e a intensificação de alguns processos de degradação socioambiental, com reflexos diversos, inclusive sociais e econômicos.

A grande rapidez dos movimentos de acumulação capitalizadora reduziu as possibilidades de estruturação de um sistema produtivo mais ajustável às oscilações do mercado e às próprias características do território, como também, menos vulnerável a impulsos provocados pelas simbologias sociais criadas em torno do dinheiro, as quais foram relativas a status derivados das posses e poderes advindos desse processo de "acumulação a jato".

4 Relativas ao lastro das relações econômicas que carregavam como selo a origem nordestina e a canalização relativamente tradicional de produtos primários in natura, ou seja, havia uma rotulação negativa atrelada à baixa modernização produtiva. Além disso, também era substancial a submissão desse mercado às regras e à logística comercial, a exemplo, respectivamente, de preços e rede de transportes, sendo mecanismos impostos pelo mercado consumidor, localizado principalmente no "coração econômico" do País-, o Sudeste. 


\subsection{DESMATAMENTO}

O desmatamento ${ }^{5}$ no PISG ocorreu ao longo do tempo como uma “questão natural e necessária” à construção de infraestrutura, como casas, escolas, prédios administrativos, estradas, canais e drenos, e à implantação e expansão dos lotes de produção (GOMES, 2005).

Para Fearnside (2005), o desgaste da cobertura vegetal frequentemente está relacionado às queimadas e à substituição da vegetação nativa pelas culturas agropecuárias. Em relação ao desmatamento associado às atividades agropecuárias, Santos e Silveira (2006) apontam o fato desse processo provocar alterações no espaço, logo não ocorre a implantação de próteses no lugar, mas a imposição à natureza da presença técnica, pois ritmos e regras humanas buscam sobrepor-se às leis naturais. Os problemas ambientais mais comuns gerados pelo desmatamento relacionam-se à exaustão de nutrientes, ao empobrecimento da biodiversidade e à erosão (FEARNSIDE, 2005).

Sobre esta discussão, Gomes (2005) enfatiza o sobre uso de fertilizantes químicos para buscar atingir a produção plena de algumas culturas. Neste raciocínio, dois aspectos fundamentam nossa linha de raciocínio inerente ao déficit de alguns nutrientes nos solos do PIG. O primeiro diz respeito ao cultivo, em muitas áreas, das mesmas plantas nos mesmos locais - monocultura, principalmente com coco e banana, cuja ausência de variedade favorece à absorção dos mesmos nutrientes, pressionando-os à exaustão. O segundo aspecto se refere à reposição deficitária de húmus - principal composto responsável pela fertilidade dos solos, oriundo principalmente da vegetação que, segundo Soares (2018), foi quase totalmente retirada. O restante encontra-se em processo de empobrecimento, sobretudo às margens do rio Piranhas (Figura 2).

\footnotetext{
Pode ser conceituado como o processo de retirada da vegetação nativa e/ou o empobrecimento da densidade vegetal, como a diminuição da altura das plantas (SAMPAIO; ARAÚJO; SAMPAIO, 2005).
} 
Figura 2 - Vegetação desgastada pela ação humana às margens do Rio Piranhas.

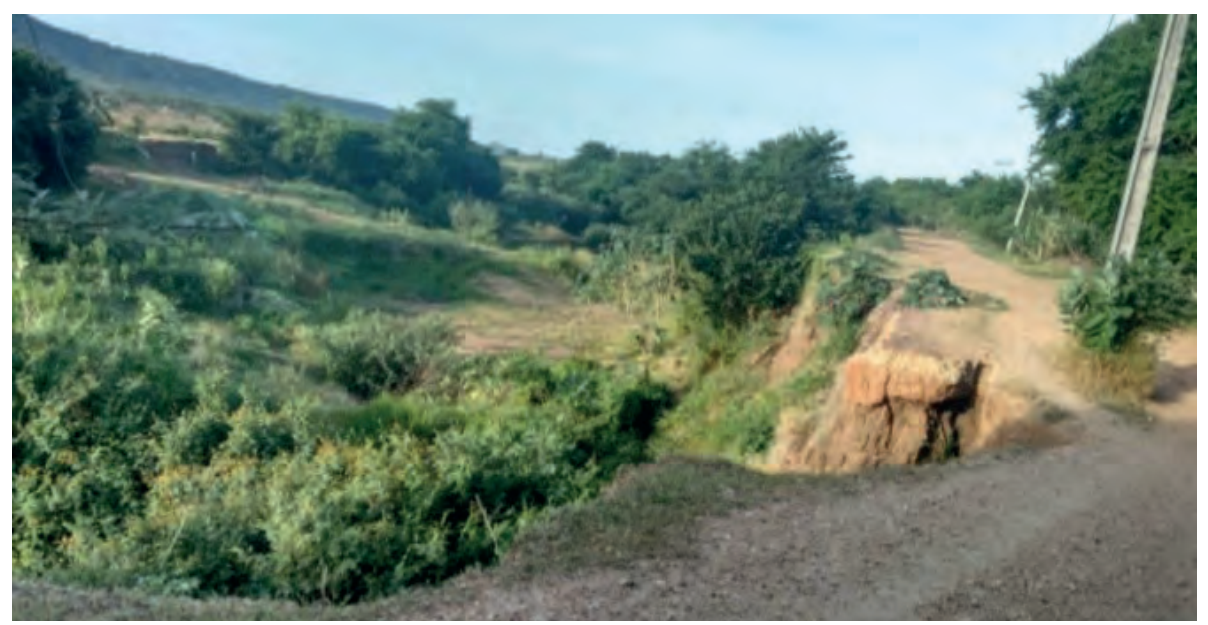

Fonte: os autores (2019).

A Figura 2 demonstra que houve a parcial retirada da proteção natural do solo - vegetação, que foi suprimida, sobretudo, para a construção de uma estrada carroçal. Em decorrência desse processo, vem ocorrendo o desgaste/erosão do solo na área. Segundo Siqueira et al. (2018), a erosão nas barreiras do rio Piranhas ${ }^{6}$ ou nas proximidades atualmente acelera o processo de assoreamento desse rio. No espaço compreendido pelo PISG, quase todo o curso do rio Piranhas tem largura superior a 10 metros, entretanto não observamos, em termos práticos, o cumprimento das recomendações previstas no Código Florestal brasileiro. Assim, entendemos que muitos produtores preferem burlar a legislação e continuarem o ciclo de devastação, ancorados no pretexto daquela exploração ser uma questão de sobrevivência. Neste contexto, as queimadas também vêm assumindo grande destaque no que se refere à degradação socioambiental no PISG, como discutiremos mais especificamente no próximo tópico.

\subsection{QUEIMADAS}

Desde o processo de implantação do PISG que as queimadas são utilizadas como forma de limpar o solo, sobretudo para a implantação e expansão das

6 Sendo que, neste sentido, o Código Florestal vigente, em seu artigo $4^{\circ}$ considera como Áreas de Preservação Permanente (APP) as faixas marginais de qualquer curso d'água natural perene e intermitente, excluídos os efêmeros, desde a borda da calha do leito regular, em largura mínima de 30 metros, para os cursos d'água de menos de 10 metros de largura; largura mínima de 50 metros, para os cursos d'água que tenham de 10 a 50 metros de largura. O mesmo artigo ainda apresenta outras orientações para cursos d'água mais largos (BRASIL, 2012). 
culturas irrigadas ou de sequeiro. O problema é que essa prática pode provocar vários danos ao ambiente, bem como aos humanos (SOARES, 2018).

Em relação a essa questão, Dorst (1973) diz que as queimadas afastam qualquer possibilidade de regeneração da vegetação, com algumas exceções. Destrói especialmente os rebentos novos e as plantas nascidas durante a estação procedente, provocando o desaparecimento gradual da vegetação. O fogo destrói a cobertura vegetal, incluindo a camada superficial de vegetais mortos que deveria gerar húmus, com isso o solo fica entregue principalmente à erosão. Esse abuso provoca uma degradação lamentável dos habitats ${ }^{7}$.

Nos últimos anos, as queimadas de incêndios acidentais e/ou criminosos também vêm ocorrendo com muita frequência no PISG, sendo que muitas vezes o Corpo de Bombeiros e a Polícia Militar, ambos da cidade de Sousa, foram acionados para auxiliar a população no controle das chamas (SOARES, 2018).

No dia 16 de outubro do ano de 2015, um incêndio de grandes proporções consumiu mais de 20 lotes e imensuráveis sonhos. Desde 2013 que os incêndios vêm trazendo pânico à população, principalmente nos meses mais secos - agosto a outubro, período cuja precipitação é praticamente inexistente e a umidade relativa do ar fica abaixo de 50\%. A título de informação, entre os meses de agosto e outubro de 2015 os incêndios devastaram mais de 40 lotes produtivos. Ocorreram vários prejuízos devido aos incêndios, a exemplo da queima total ou parcial das plantações, das instalações elétricas pertencentes à Distribuidora de Energia S/A (ENERGISA) e das tubulações plásticas de transporte de água dos canais, drenos, cacimbões e poços artesianos até as plantações. Além da aflição e prejuízos, vale ressaltar que os efeitos das queimadas praticadas ao longo dos anos foram semelhantes, até certo ponto, aos da retirada da cobertura vegetal, ou seja, culminaram com a redução da fertilidade dos solos, o empobrecimento da biodiversidade e a erosão, embora com dois agravantes: a poluição atmosférica e a intensificação de problemas de saúde pública, principalmente respiratórios (SOARES, 2018).

Além dos problemas ambientais e socioeconômicos decorrentes dos incêndios, como já vimos neste contexto, também vale ressaltar o fato de que, desde sua implantação, o PISG vem sendo arranhado, em termos socioambientais, em decorrência da utilização excessiva de insumos químicos na agricultura irrigada, discussão que será esmiunçada no tópico a seguir.

Que também pode provocar outros problemas, como a liberação de gases tóxicos para a atmosfera, principalmente monóxido de carbono e dióxido de carbono, que contribuem para a intensificação do efeito estufa e o agravamento de doenças respiratórias, cardíacas, dentre outras (SAMPAIO; ARAÚJO; SAMPAIO, 2005). 


\subsection{USO EXCESSIVO DE INSUMOS QUÍMICOS NA AGRICULTURA IRRIGADA}

No início da implantação do PISG era preciso fazer a terra produzir incessantemente para garantir a sobrevivência das famílias, que eram formadas geralmente por mais de 10 filhos, além do pai e da mãe. Aí surge outro problema ainda mais grave, que foi o uso indiscriminado dos insumos químicos ${ }^{8}$ (GOMES, 2005). Conforme Nunes e Sousa (2018), os insumos superquímicos fazem parte da sesta de inovações incorporadas à agricultura mundial, especialmente a partir da década de 1950. No Brasil, os referidos produtos chegaram por volta de 1970, esses amparados pelo agronegócio (a exemplo de grandes projetos de irrigação), bem como pelo discurso de combate à fome que assolava o País à época, (problema esse que ainda persiste atualmente).

Os agrotóxicos foram e são utilizados até hoje na agricultura para matar bactérias, fungos, ervas daninhas, insetos, roedores e quaisquer organismos que possam prejudicar colheitas, diminuindo a quantidade e qualidade dos produtos alimentares (BARBOSA, 2014, p. 85). Segundo Barbosa (2014), o uso excessivo de insumos químicos pode causar problemas sérios relacionados à contaminação dos componentes bióticos e abióticos de determinados espaços. As substâncias tóxicas presentes nesses produtos podem ser incorporadas na cadeia alimentar e, por conseguinte, contaminar grandes quantidades de seres vivos. No caso dos fertilizantes, por exemplo, o fosfato e o nitrato presentes em sua composição química são os principais responsáveis pela eutrofização das águas devido à formação de ambientes propícios ao desenvolvimento e proliferação de algas, as quais consomem o oxigênio aquático.

Em trabalho de campo realizado no PISG, Siqueira et al. (2018) constataram que o uso de agrotóxicos e fertilizantes é muito elevado. Das pessoas entrevistadas em sua pesquisa, mais de $96 \%$ responderam que usavam agrotóxicos na produção agrícola, sendo que a maioria destas também disse que usava fertilizantes químicos. Para Gomes (2005), os efeitos quanto ao uso excessivo desses produtos no sistema produtivo do PISG vêm repercutindo negativamente, sobretudo na fertilidade dos solos, na qualidade das águas e nos produtos e na saúde da população local.

A respeito dos efeitos relacionados à problemática em discussão, com base nas palavras de Gomes (2005) e Siqueira et al. (2018), dois aspectos chamam

\footnotetext{
Sendo importante frisarmos que a modernização da agricultura proporcionou o uso de uma diversidade de insumos, como agrotóxicos e fertilizantes. Os agrotóxicos também denominados de pesticidas, praguicidas ou fitossanitários se espalharam pelo mundo após sua produção e expansão durante a Segunda Guerra Mundial (STOPPELLI, 2005, p. 92).
} 
a atenção. O primeiro é o seguinte: para garantir produção satisfatória os colonos pulverizavam os coqueirais com grandes quantidades de veneno pelo menos três vezes ao mês. Para agravar a situação, a pressão de mercado, de certa forma, "indicou” o uso de aproximadamente 20 tipos de venenos. Isso com vista à potencialização da produção e foco maior no lucro para os participantes dessa dinâmica relativa à comercialização dos produtos. É preciso utilizar muitos e variados tipos de agrotóxicos para conseguir produzir frutos com aspecto, tamanho e sabor exigidos pelo mercado consumidor. Sobre essa questão, cabe enfatizar o aumento da incidência de casos de câncer, provavelmente relacionados à contaminação durante a aplicação, sem a proteção devida, do veneno nas culturas, ou a partir da ingestão de água e alimentos contaminados. Várias pessoas da região do PISG realizaram exames de sangue e constataram a existência de muitas substâncias tóxicas indicadoras de variados tipos de canceres.

O segundo aspecto, considerado de elevada relevância, foi o fato de alguns produtores plantarem em determinadas faixas de terras e as culturas não se desenvolviam, tampouco produziam satisfatoriamente, ou seja, em algumas áreas o solo tinha pouca produtividade ou praticamente inexistente. Diante da constatação da improdutividade de alguns terrenos, os produtores praticamente abandonavam essas áreas.

Mesmo com a grande utilização dos agrotóxicos para conter a crescente ocorrência de pragas nas plantações, bem como o uso de fertilizantes químicos para corrigir o déficit de alguns nutrientes no solo, a produção vinha apresentando quedas em muitas áreas (SILVA NETO, 2013). A utilização excessiva de agrotóxicos e fertilizantes causou a contaminação das culturas e sérios danos à biota do solo, a fauna e a outros componentes ambientais, como o lençol freático, os córregos e o rio Piranhas; bem como às populações humanas atingidas direto ou indiretamente pelo conjunto combinado dos efeitos ambientais (SIQUEIRA et al., 2018).

Cada um dos processos de degradação socioambiental, discutido até aqui, foi analisado mediante suas causas e principais efeitos, cujos desarranjos socioambientais influenciaram no processo de desmantelamento da estrutura produtiva do PISG. Daremos sequência ao debata colocando em tela a questão do uso inadequado da água no processo de irrigação no PISG ao longo de sua história, discussão essa expressa em continuidade no tópico abaixo.

\subsection{USO INADEQUADO DA ÁGUA NO PROCESSO DE IRRIGAÇÃO}

Um dos principais elementos que nos ajuda a compreender o uso irracional das águas no PISG diz respeito ao fato do Açude de São Gonçalo 
ter atingido sua capacidade máxima em fevereiro de 2011 - 44,6 milhões de metros cúbicos de água, e permaneceu cheio até o mês de maio daquele mesmo ano, segundo a Agência Executiva de Gestão das Águas do Estado da Paraíba (AESA, 2020a). Contudo, foi decretado racionamento hídrico no final do ano de 2012, devido ao fato do reservatório ter sido praticamente esvaziado, ficando com aproximadamente 30\% de sua capacidade máxima (SOARES, 2018).

A água do reservatório 'desapareceu' em pouco mais de um ano, mesmo com a relativa recarga a partir da quadra chuvosa ${ }^{9}$ de 2012 . Esse processo foi influenciado, sobretudo, pela grande expansão de algumas culturas de altíssima necessidade hídrica - coco e banana, irrigadas predominantemente por meio da utilização do defasado sistema superficial (QUEIROZ; RODRIGUES, 2019). Esse modelo de irrigação também foi um dos grandes responsáveis pelo elevado desperdício de água e pelo avanço de processos de degradação socioambiental (SIQUEIRA et al., 2018). Vislumbrando a ideia de Santos (2015), percebemos, neste contexto, que a mercantilização da natureza teve relação direta com o evento relativo à falta de água no PISG, ou seja, o mercado exerceu suas forças exploratórias com pressões superiores à capacidade produtiva do território uma vez que aquele sistema produtivo ainda inconsolidado era desprovido de condições básicas para garantir uma logística mercantil pautada na racionalidade, quanto à utilização dos recursos naturais, especialmente da água.

No Semiárido brasileiro, as mais de três mil horas anuais de insolação e os ventos relativamente secos durante a maior parte do ano associados a grande utilização inadequada do líquido vida na agricultura são variáveis que ajudam a explicar o processo de salinização dos solos, principalmente em áreas irrigadas de alguns perímetros, como o de Sousa (PB) (REBOUÇAS, 1997).

O processo de salinização na região de São Gonçalo teve origem antes da implantação do PISG. À época, o DNOCS constatou algumas faixas de solos salinizados por meio de análises laboratoriais. Em seguida, adotou algumas medidas sem êxito, como lavagens e a aplicação de corretivos químicos e orgânicos para recuperar essas áreas (GOMES, 2005).

Para Gomes (2005), o avanço do processo de salinização ocorreu de forma potencial, principalmente devido à drenagem superficial ineficiente e à utilização predominante da irrigação superficial, caracterizada pela liberação da água em valas precárias e permeáveis. Assim, devido aos desperdícios provocados pela inundação, a água empossada contribuiu para a formação de crostas salinas sobre os solos de muitas áreas do Perímetro (Figura 3).

9 Na qual a precipitação total registrada no PISG foi de 544,5 milímetros (AESA, 2020b). 
Figura 3 - Área em processo de salinização localizada no distrito de São Gonçalo (PISG).

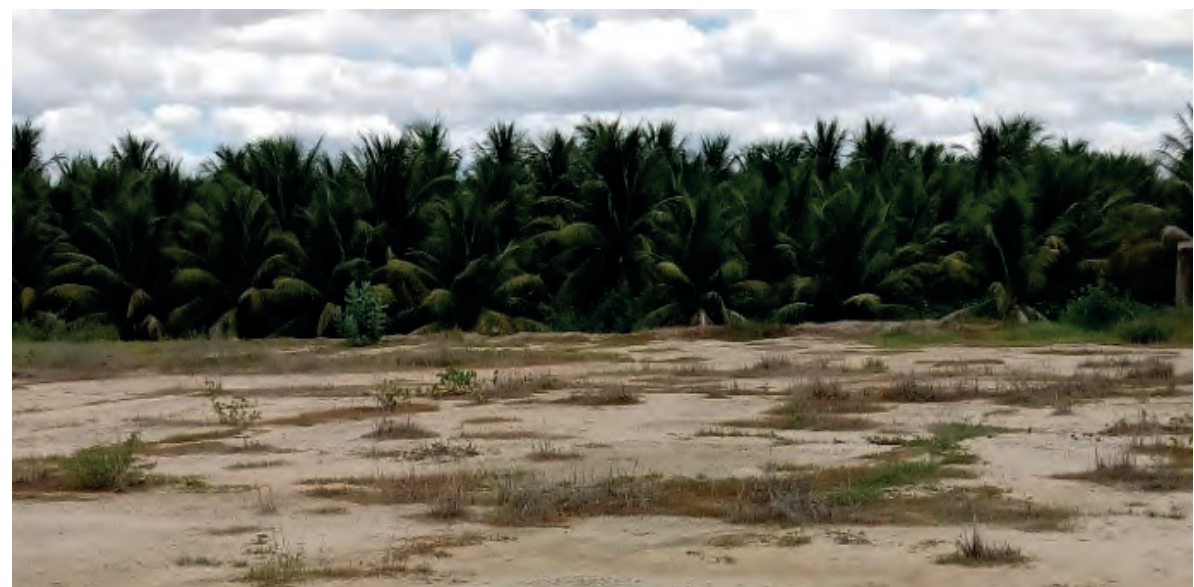

Fonte: os autores (2019).

Ao observarmos a Figura 3, podemos identificar algumas áreas cujos solos estão praticamente sem vida, isto fica evidente nos espaços desprotegidos em razão da ausência de vegetação. Apenas as plantas mais resistentes à salinização ${ }^{10}$ sobrevivem no local, como algumas espécies de herbáceas. São necessários vários anos de descanso para que esses solos se recuperem e voltem a produzir satisfatoriamente (SIQUEIRA et al., 2018).

Os sais em excesso podem prejudicar o processo de germinação das sementes. Ao serem absorvidos pelas plantas, também acabam prejudicando o desenvolvimento destas, haja vista que são formados nódulos em suas raízes, processo que dificulta a absorção de água e nutrientes. Fora isso, os sais que são incorporados excessivamente pelas plantas provocam problemas metabólicos e celulares, tornando-as raquíticas, amareladas e podendo levá-las à morte (PEDROT'TI et al., 2015).

Algumas culturas são mais sensíveis do que outras à salinização dos solos, a exemplo do arroz e do coco, que conseguem produzir em áreas com razoável nível de salinidade; mas o feijão e o pimentão não têm a mesma tolerância e

10 Sendo cabível ressaltarmos que as águas superficiais e subterrâneas fazem parte de uma das principais dinâmicas da natureza - o ciclo hidrológico. As águas superficiais ao escoarem sobre rochas e solos podem adquirir quantidades significativas de sais. Já as águas subterrâneas também podem adquirir sais no processo de dissolução das rochas em contato com o lençol freático. O processo de evaporação faz uma "filtragem" na água, propiciando a elevação do vapor até as camadas superiores da atmosfera e a precipitação dos sais sobre as camadas superficiais dos solos, principalmente cloreto de sódio, cálcio e magnésio. A inundação dessas áreas acaba espalhando os sais sobre as camadas superiores dos solos, aumentando a dimensão espacial da salinização (PEDROTTI et al., 2015). 
acabam tendo produções deficitárias ou morrendo. A concentração de sais na superfície dos solos normalmente reduz a fertilidade e aumenta a tendência do desenvolvimento de processos de desertificação (SILVA NETO, 2013).

Conforme o mesmo autor supracitado, o processo de salinização foi intensificado com a utilização demasiada de águas de baixa qualidade, de fontes subterrâneas captadas principalmente por meio de cacimbões e/ou poços artesianos.

No período de 2012 a 2017, o PISG enfrentou um dos maiores racionamentos hídrico de sua história, isso devido ao fato dos Açudes de São Gonçalo e Engenheiro Ávidos não terem acumulado água o suficiente para encher e garantir a continuidade da irrigação. Aliás, faltou água até para o consumo humano. Foi nessa emergência que muitos produtores construíram algumas obras de captação de água do lençol freático. Inicialmente, o objetivo era salvar as plantações que sofriam com a desidratação - batalha fracassada na maioria dos casos. Depois, a prioridade passou a ser a obtenção de água para o consumo humano e a dessedentação animal (QUEIROZ; RODRIGUES, 2019).

Com base nas palavras de Siqueira et al. (2018), é importante frisar que praticamente não existe culturas irrigadas com efetiva produção na região compreendida pelo PISG (Figura 4). Além disso, segundo Araújo et al. (2018), todos os pomares de goiaba, maracujá, graviola e manga foram extintos devido à suposta falta de água, ataques de pragas ou à improdutividade dos solos.

Figura 4 - Vista panorâmica de recorte espacial do PISG.

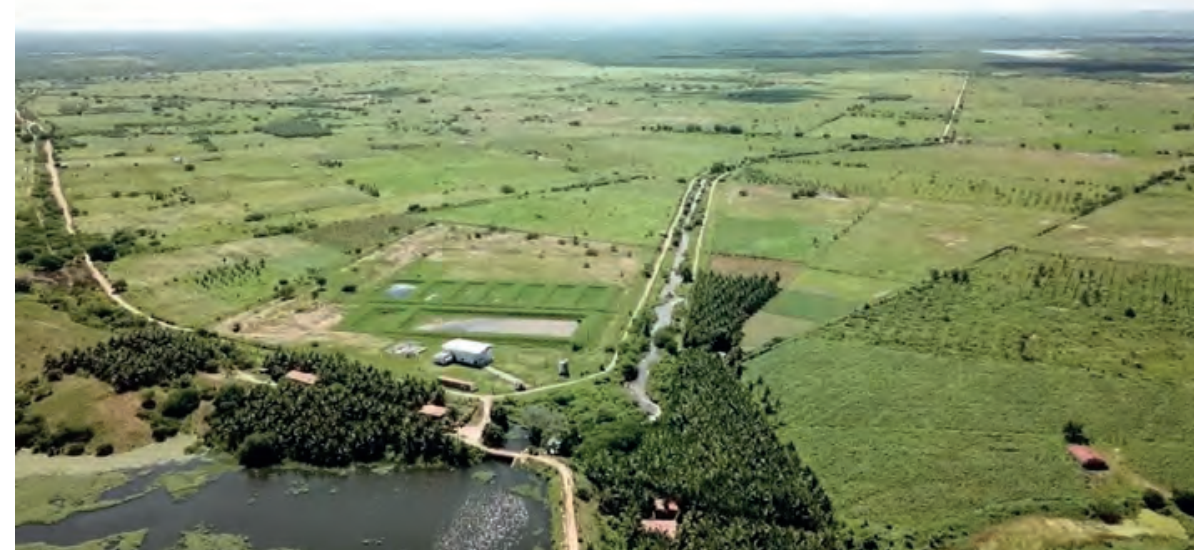

Fonte: Dantas (2019, n. p.). 
Conforme a Figura 4, a qual representa parte do espaço do PISG registrado no dia 16 de abril de 2019, podemos observar que as culturas permanentes de coco e banana, que eram predominantes na área, se restringiam a pequenos enclaves situados às margens da Estação de Piscicultura, nas proximidades do Açude de São Gonçalo, onde a umidade natural era suficiente apenas para manter essas culturas vivas. À época, as demais áreas do Perímetro se encontravam em ócio, ou ocupadas com culturas de sequeiro. Contudo, observamos que nestes dois últimos anos (2019-2020), o PISG lentamente vem se ressignificando, porém com base no mesmo sistema produtivo que colapsou anteriormente.

Sobre as possíveis causas e consequências da decadência produtiva, Sampaio, Araújo e Sampaio (2005) corroboram dizendo que o processo de salinização dos solos e outros impactos socioambientais podem acarretar maiores custos produtivos e, mesmo assim, dificilmente os resultados esperados serão alcançados. Em decorrência dessa dinâmica indesejável pode haver prejuízos ambientais, reduções no nível de renda e piora da qualidade de vida da população afetada pelos efeitos da degradação.

Os efeitos mais consistentes relacionados à redução da qualidade de vida estão atrelados à desnutrição, epidemias e migrações (SILVA NETO, 2013). No que concerne às migrações, Silva et al. (2017) e Siqueira et al. (2018) dizem que o fenômeno é marcante no PISG, cujos fluxos são orientados para várias regiões do País.

Atualmente, muitos dos colonos que decidiram permanecer no 'perímetro seco' estão desempregados, outros conseguiram trabalho principalmente em indústrias de laticínios, lojas de Sousa e dos municípios vizinhos, bem como serviços de crediário, manicure, cabelereiro(a), faxineiro(a), dentre outros. Há também muitas pessoas sobrevivendo com rendimentos advindos, sobretudo, de benefícios trabalhistas e assistencialistas, como aposentadorias e o Bolsa Família, respectivamente (QUEIROZ; RODRIGUES, 2019).

Diante do quadro de declínio produtivo e instabilidade econômica e social, neste contexto fica exposto o quanto foi insustentável o modelo produtivo utilizado no PISG ao longo de sua história, evidenciando assim o quanto foi perniciosa a inserção do referido espaço na dinâmica do capital desinteressada na sustentabilidade do lugar. Neste prisma, entendemos que o processo de reconstrução do PISG deve ser colocado em pauta de desenvolvimento, o qual precisa englobar vários fatores, sobretudo a gestão participativa e integrada dos recursos naturais, focalizando especialmente a água e o solo. A seguir apresentaremos as considerações finais do trabalho. 


\section{CONSIDERAÇÕES FINAIS}

Com base nas discussões fomentadas neste artigo, consideramos que o DNOCS, enquanto principal articulador do desenvolvimento do PISG, não reuniu condições efetivas para garantir a racional exploração dos recursos naturais, tendo em vista o princípio da conservação. Um fator que ilustra negativamente essa questão diz respeito a não modernização do sistema de irrigação.

Os colonos do Perímetro também não reuniram condições que viabilizassem a gestão compartilhada de suas atividades diante das fragilidades administrativas e estruturais apresentadas pelo DNOCS. Por outro lado, esses mesmos produtores associados às estruturas administrativas, também não tiveram forças para controlar a pressão exercida pelo mercado consumidor, que buscava cada vez mais produtos num ritmo superior à capacidade produtiva.

Assim, visualizamos neste contexto um conjunto de fatores que denunciam a apropriação dos recursos naturais ao passo da ausência de políticas públicas eficientes e da inaplicabilidade das legislações reguladoras do uso dos recursos naturais presentes no PISG.

A histórica gestão deficitária das riquezas naturais, sobretudo das águas, e a pressão exercida pelo mercado quanto à superprodução a qualquer custo ambiental, influenciaram sobremaneira no desmantelamento do sistema produtivo do PISG. A degradação socioambiental também contribuiu para a formação de um 'perímetro seco' e desprovido da fartura comum em períodos pretéritos. Em relação à economia, as relações comerciais em múltiplas escalas espaciais foram desarticuladas, justificando a incapacidade do mercado no tocante à garantia da racionalidade no sistema produtivo.

Os efeitos do processo de desmantelamento da estrutura produtiva do PISG relacionam-se, efetivamente, à diminuição dos níveis de emprego e renda, e consequentemente à redução da qualidade de vida da população. Como dizem Silva et al., (2017) e Siqueira et al., (2018), a somatória desses efeitos vem contribuindo para que muitas famílias procurem melhores condições de vida em outras regiões do Brasil, caracterizando assim um fluxo migratório.

Portanto, as discussões fomentadas neste artigo nos levaram a compreender o fato do objetivo estatal quanto à modernização da agricultura no PISG não ter sido alcançado, pelo contrário, houve sucateamento da estrutura produtiva. Além disso, também fica evidente, neste contexto, o fato de o Perímetro atravessar tempos nebulosos do ponto de vista ambiental e socioeconômico, sendo necessária sua revitalização. 
Como proposta para futuros estudos, sugerimos pesquisas que avaliem os processos de degradação socioambiental desencadeados ao longo do tempo no PISG mediante a percepção das pessoas que vivenciaram e/ou ainda vivenciam tal realidade. Assim, poderá ser realizado o 'raio x' da transformação antropológica da paisagem segundo as memórias de seus habitantes. Por fim, se seguem as referências bibliográficas.

\section{REFERÊNCIAS}

AESA. Meteorologia - Chuvas. AESA, João Pessoa, 2020a. Disponível em: http://www.aesa.pb.gov.br/aesa-website/meteorologia-chuvas/. Acesso em: 03 ago. 2020 .

AESA. Volumes de açudes: açude São Gonçalo. AESA, João Pessoa, 2020b. Disponível em: http://www.aesa.pb.gov.br/aesa-website/monitoramento/ volume-acude/?id_acude=9659. Acesso em: 03 ago. 2020 .

ARAÚJO, D. C.; VIEIRA, A. S.; QUEIROGA, F. A.; FIGUEIREDO, F. N. L.; SILVA, L. B.; SARMENTO, R. C. S. S. Proposta de um modelo de gestão para o uso eficiente da água no perímetro irrigado de São Gonçalo no Sertão paraibano.

Revista Brasileira de Gestão Ambiental, Pombal, v.12, n. 1, p. 43-57, 2018.

BARBOSA, V. A última gota. 1 ed. São Paulo: Planeta, 2014. 247 p.

BRASIL. Lei n ${ }^{\circ}$ 12.651, de 25 de maio de 2012. Dispõe sobre a proteção da vegetação nativa [...]. Brasília, DF: Presidência da República, [2012]. Disponível em: http://www.planalto.gov.br/ccivil_03/_Ato2011-2014/2012/Lei/L12651. htm. Acesso em: 13 jan. 2019.

DANTAS, L. VÍDEO! Imagens aéreas mostram obras e por onde é liberada a água do Açude de São Gonçalo. Blog do Levi, Sousa, 16 abr. 2019. Cotidiano. Disponível em: https://blogdolevi.portaldiario.com.br/2019/04/16/videoimagens-aereas-mostram-obras-e-por-onde-e-liberada-a-agua-do-acude-de-saogoncalo/. Acesso em: 03 out. 2019.

DNOCS. Perímetro Irrigado de São Gonçalo. DNOCS, Fortaleza, 2020. Disponível em: http://www.dnocs.gov.br/ dnocs/doc/canais/perimetros_ irrigados/pb/sao_goncalo.htm. Acesso em: 06 out. 2020.

DORST, J. Antes que a natureza morra: por uma ecologia política. Tradução Rita Buongermino. São Paulo: Edgard Bblucher, 1973. 416 p.

EMBRAPA. Sistema brasileiro de classificação de solos. 2. ed. Rio de Janeiro: Embrapa solos, 2006. 306 p. 
FEARNSIDE, P. M. Desmatamento na Amazônia brasileira: história, índices e consequências. Megadiversidade, Belo Horizonte, v. 1, n. 4, p. 113-123, 2005.

GERHARDT, T. E.; SILVEIRA, D. T. Método de pesquisa. Editora da UFRGS, 2009. 120p.

GIUMBELLI, E. Para além do "trabalho de campo": reflexões supostamente malinowskianas. Revista Brasileira de Ciências Sociais, [S. l.], v. 17, n. 48, p. 91-107, 2002.

GOMES, R. A. A qualidade de vida das famílias no Perímetro Irrigado de São Gonçalo: ética e racionalidade. 2005. 234 f. Tese (Doutorado em Sociologia) - Programa de Pós-Graduação em Sociologia, Universidade Federal do Pernambuco, Recife, 2005.

LEFF, H. Racionalidade ambiental: a reapropriação social da natureza. Tradução Luís Carlos Cabral. Rio de Janeiro: Civilização Brasileira, 2006. 555 p.

MARCONI, M. A.; LAKATOS, E. M. Fundamentos de metodologia científica. 5. ed. São Paulo: atlas, 2003. 312 p.

NASCIMENTO, F. R. Degradação ambiental e desertificação no Nordeste brasileiro. O contexto da Bacia Hidrográfica do Rio Acaraú - Ceará. 2006. 355 f. Tese (Doutorado em Geografia) - Programa de Pós-Graduação em Geografia, Universidade Federal Fluminense, Niterói, 2006.

NUNES, J. V.; SOUSA, M. L. M. A Geografia aplicada ao semiárido brasileiro: desafios e perspectivas. In: OLIVEIRA, V. P.; SOUSA, M. L. M. Agricultura e degradação ambiental no Perímetro Irrigado de Morada Nova, Baixo Banabuiú - Ceará. Fortaleza: Expressão Gráfica e Editora, 2018, p. 343-356.

PEDROT'TI, A. CHAGAS, R. M.; RAMOS, V. C.; PRATA, A. P. N.; LUCAS, A. A. T.; SANTOS, P. Causas e consequências do processo de salinização dos solos. Revista Eletrônica em Gestão, Educação e Tecnologia Ambiental, Santa Maria, v. 19, n. 2, p. 1308-1324, 2015.

QUEIROZ, C. N. O processo de construção da pequena produção (familiar) modernizada (O caso do Perímetro Irrigado de São Gonçalo - PB). 1993. 152 f. Dissertação (Mestrado em Sociologia) - Programa de Pós-Graduação em Sociologia, Universidade Federal da Paraíba, Campina Grande, 1993. 
QUEIROZ, J. G. Os vieses da questão hidrossocial e os penduricalhos produtivos do perímetro irrigado de São Gonçalo - Paraíba: quais os arranhões e as ferrugens que o desgastaram durante o período de 2012 a 2017 ?. 2019, 162 f. Dissertação (Mestrado em Planejamento e Dinâmicas Territoriais no Semiárido) - Programa de Pós-Graduação em Planejamento e Dinâmicas Territoriais no Semiárido), Universidade Estadual do Rio Grande do Norte, Pau dos Ferros, 2019.

QUEIROZ, J. G.; RODRIGUES, J. F. Sustentabilidade, políticas públicas e interdisciplinaridade no semiárido. In: ALVES, L. S. F; BEZERRA, J. A.; SILVA, M. M. N. (ed.). Perímetro Irrigado de São Gonçalo - Paraíba: uma análise sobre o declínio da produção agropecuária e suas implicações nas relações comerciais do local com o regional, o nacional e o internacional. Natal: CCHLA, 2019, p. 39-54.

REBOUÇAS, A. C. Água na região Nordeste: desperdício e escassez. Estudos Avançados, São Paulo, v.11, n. 29, p. 127-154, 1997.

SAMPAIO, E. V. S. B; ARAÚJO, M. S. B.; SAMPAIO, Y. S. B. Impactos ambientais da agricultura no processo de desertificação no Nordeste do Brasil. Revista de Geografia do Departamento de Ciências Geográficas, Recife, v. 22, n. 1, p. 93-113, 2005.

SANTOS, M. Por uma outra globalização: do pensamento único à consciência universal. 24 ed. Rio de Janeiro: Record, 2015. 174 p.

SANTOS, M; SILVEIRA, M. L. O Brasil: território e sociedade no início do século XXI. 9 ed. Rio de Janeiro: Record, 2006. 474 p.

SILVA, J. B; GUERRA, L. D.; IORIS, A. GOMES, R. A. Conflitos sociopolíticos, recursos hídricos e programa um milhão de cisternas na região semiárida da Paraíba. Novos Cadernos NAEA, Belém, v. 18, n. 2, p. 69-92, 2015.

SILVA, S. N.; LOPES, F. G.; ANDRADE, F. E.; FERREIRA, C. B.; DANTAS, M. C. A. M.; SIQUEIRA, E. C. Efeitos da escassez hídrica na economia do perímetro irrigado de São Gonçalo, Paraíba. Revista Verde de Agroecologia e Desenvolvimento Sustentável, Pombal, v. 12, n. 1, p. 132-137, 2017.

SILVA NETO, M. F. A problemática da salinização do solo no Perímetro Irrigado de São Gonçalo - PB. 2013. 139 f. Dissertação (Mestrado em Geografia) - Programa de Pós-Graduação em Geografia, Universidade Federal da Paraíba, João Pessoa, 2013. 
SIQUEIRA, E. C.; SILVA, S. N.; LOPES, F. G.; ANDRADE, F. E.; BRAGA, C. F. Avaliação dos impactos da seca no Perímetro Irrigado de São Gonçalo - PB. Divulgação Científica e Tecnológica do IFPB. Revista Principia, João Pessoa, v. 1, n. 40, p. 21-27, 2018.

SOARES, J. A. Memorial de um sertão. Sousa: [s. n.], 2018. 184 p.

STOPPELLI, I. M. B. S.; MAGALHÃES, C. P. Saúde e segurança alimentar: a questão dos agrotóxicos. Ciência \& Saúde Coletiva, Rio de Janeiro, v. 10, p. 91-100, 2005.

TRIENTA, F. T.; FILHO, J. R. F.; SANT'ANA, A. P.; RABELO, L. M. Metodologia de pesquisa bibliográfica com a utilização de método multicritério de apoio à decisão. Produção, São Paulo, v. 24, n. 3, p. 508-520, 2014. Disponível em: http://www.scielo.br/pdf/prod/2013nahead/aop_prod0312.pdf. Acesso em: 15 set. 2019. 
